\title{
Study on Restoration Materials for Historical Silty Earthen Sites Based on Lime and Starch Ether
}

\author{
Dequan Kong $\mathbb{D}^{1},{ }^{1}$ Jianxun Chen, ${ }^{2}$ Rong Wan $\mathbb{D}^{1,3}$ and Hongli Liu ${ }^{1}$ \\ ${ }^{1}$ School of Civil Engineering, Chang'an University, Xi'an 710061, China \\ ${ }^{2}$ School of Highway Engineering, Chang'an University, Xi'an 710064, China \\ ${ }^{3}$ State Key Laboratory of Green Building in Western China, University of Architecture \& Technology, Xi'an 710055, China \\ Correspondence should be addressed to Dequan Kong; dkong906@yahoo.com
}

Received 10 February 2020; Revised 18 May 2020; Accepted 1 June 2020; Published 28 June 2020

Academic Editor: Fernando Lusquiños

Copyright (c) 2020 Dequan Kong et al. This is an open access article distributed under the Creative Commons Attribution License, which permits unrestricted use, distribution, and reproduction in any medium, provided the original work is properly cited.

The relics built with soil are called earthen archaeological sites. Many silt earthen sites exposed to natural environment get seriously damaged and thus require urgent restoration with suitable materials. Previously, lime and glutinous rice slurry were used in the construction of earthen sites. However, lime is usually used in clay, and glutinous rice pulp is difficult to prepare and use on a large scale. Therefore, in this study, starch ether was selected to replace glutinous rice pulp. Lime and starch ether were added to silt as single or double additives, respectively, to prepare the corresponding single-mixed and multiple-mixed modified soil samples. Furthermore, the direct shear test and compression test were carried out and the optimum content was determined. The strength and durability of optimum modified materials were compared with those of the original site soil. When the lime content was $9 \%$ or the concentration of starch ether solution was $5 \%$, the shear strength and compression resistance ability of single-mixed modified soil were improved significantly. When lime content was $6 \%$ and starch ether solution was 5\%, the strength of multiple-mixed modified soil was the best, and the maximum cohesion and internal friction angle were 51.1 and $3.37 \%$ higher than those of singlemixed soil, respectively. The strength and durability of the optimum modified soil were similar to or higher than those of the site soil. Thus, it is feasible and effective to use lime together with starch ether as restoration material for silty earthen sites.

\section{Introduction}

As a historical and cultural country, China has a large number of relics. The relics mainly built with soils are called earthen archaeological sites. Noteworthy, there are more than 900 earthen sites listed in the National Key Cultural Relics Protection Catalog of China [1,2]. The Northwest China region is the origin area and one of the cradles of Chinese civilization and the starting point of the famous ancient Silk Road. Therefore, the historical and cultural relics, in particular the earthen sites, are widespread in this area, such as the city wall of Han dynasty, the Terracotta army, the mausoleum of Xixia dynasty, and the Tongwan City. These earthen sites are representatives of ancient architectural technology and carriers of human culture, which contain rich historical information and have irreplaceable important value.
Many earthen sites are large in scale, which are difficult to cover and isolate for protection. Most of them remain usually exposed and thus get significantly affected by natural environment. Many environmental factors, such as sandstorm, rainwater, biological properties, and atmospheric temperature, can cause damage to earthen sites and gradually affect their stability and safety. Recently, some earthen sites have collapsed and even disappeared. Therefore, a lot of more systematic explorations are urgently demanded to protect and restore these earthen sites.

Building materials are one of the important contents for restoration of earthen sites [3]. In particular, with the development of modern material technology, the study of reinforcement and restoration materials for earthen sites has been the hot research topic for scholars [4-6]. Among the commonly used restoration materials for earthen sites, inorganic materials include potassium silicate (PS), sodium 
silicate, aluminum silicate, barium hydroxide, and calcium hydroxide. Moreover, organic polymer materials include silicone resins and organic polymer materials. Inorganicorganic complex materials as restoration materials include potassium silicate-methyl triethoxysilane combination. Till date, extensive research efforts have been devoted to the study in this field at the global scale. As early as 1960s, organosilicon oligomers were used to reinforce the earthen site in Yokohama by the National Institute for Cultural Research of Japan [7]. In 1969, Giacomo studied the protection of dry bricks from the Seleucia and Hatra sites in Iraq and injected ethyl silicate-ethanol combination into the site for reinforcement [8]. In 1975, a mixture of tetraethyl tetraethoxysilane and ethanol was applied to protect the surface of an earthen site in Peru [9]. Furthermore, tetraethyl orthosilicate and polyurethane were selected as restoration materials, and an Indian native earthen site in New Mexico was reinforced with these materials in 1990 [10]. In 2005, Degirmenci and Baradan carried out tests to reinforce the site soil using a mixture of hydrated lime, water, brick powder, and fly ash [11].

Moreover, many scholars have also proposed new soilmodified materials, which also provide new possibilities for the restoration of Earth sites. For example, Arab et al. confirmed the feasibility and effectiveness of using sodium alginate biopolymer for treating weak cohesive subgrades, in particular, under repeated traffic loads for pavement construction applications [12]. Liu et al. showed that the use of lignin or lignocellulose material could effectively improve the engineering properties of soil $[13,14]$. Adhikari et al. reported that geopolymer binder could be used to stabilize soil and exhibited good stabilization effect [15]. All these studies are advanced and inspiring.

In recent years, progressively a greater number of Chinese scholars have conducted detailed researches on the protection of ruins and achieved a series of useful results [16]. In particular, since the promulgation of the Cultural Relics Protection Law of the People's Republic of China, the development methods for the protection of cultural relics have been promoted [17-19]. Zhang et al. reinforced the partial area of Banpo earthen site through using self-made organosilicon materials, and the protection effect was found to be good [20, 21]. In 1990, Li et al. established a theory and technology of reinforcement of earthen sites based on PS materials and applied it in many famous earthen sites such as Dunhuang, Yumenguan, Banpo, and Hecang city [22-24]. Over the same period, Zhang et al. used acrylic resin material to reinforce the Terracotta Army site [25-27]. Furthermore, Pang et al. used the emulsion compound material to protect the Jiaohe city site $[28,29]$. In 2009, Chai et al. studied the reinforcement and protection methods for Tangiia No. 2 ancient soil kiln using tetraethyl orthosilicate [30]. Although the earthen sites can be strengthened using the abovementioned materials, their appearance and engineering properties also change to certain extent after reinforcement, and the damage of some earthen sites even becomes more severe. For example, PS material, mainly composed of high modulus PS, is an effective reinforcing material for earthen sites. However, associated problems such as brittleness, shrinkage, and alkali leaching emerged after these materials were used for reinforcing the earthen sites; thus the longterm environmental durability of the materials required improvement [31-34]. Another example is that though acrylic resin adhesives can improve the strength of the reinforced soil, they may also cause secondary weathering damage to the site [35].

Early research on restoration materials was mainly focused extensively on modern materials and less on traditional materials. In recent years, significant research efforts have been devoted to the study on traditional materials in the restoration of earthen sites. A number of common traditional materials, such as tung oil, glutinous rice pulp, and lime, have been used as building materials for historical earthen sites in ancient time. These materials are nontoxic, environment-friendly, and economical, with high strength and good durability. Peng et al. revealed that, after mixing with glutinous rice pulp, the mechanical properties of the triad soil became better, the impermeability was significantly improved, and the difference in appearance was not large [36]. Ji et al. tested the engineering properties of the modified soil prepared with different concentrations of glutinous rice pulp and analyzed the relationship between the concentration of glutinous rice pulp and the strength of the modified soil [37]. Through a series of experiments, Zeng et al. found that glutinous rice pulp exhibited apparent reinforcement effect on mortar [38-40]. As a traditional building material, lime can effectively improve the strength and impermeability of clay [41]. For example, Al-Mukhtar et al. studied the expansive properties of lime-solidified loess and discussed the optimum solidification concentration of lime [42]. Boardman et al. analyzed the reason for the increase of early strength of lime soil through experiments [43]. Pancar and Akpinar pointed out that the use of lime to strengthen the roadbed could effectively reduce the settlement [44].

In the existing researches, glutinous rice pulp is mainly used in mortar or triad soil as reinforcement, and lime is mainly utilized in stabilizing and reinforcing clay. Many earthen sites in Northwest China are located in silt areas. Considering the convenience and economic factors, silt is used as the main building material for earthen sites in this area. Silt has unique engineering characteristics. The poor particle gradation makes silt difficult to compact and causes poor engineering properties. The study on whether the lime and glutinous rice pulp are suitable for the restoration of silty earthen sites still needs further systematic explorations. Moreover, due to the difficulty to produce and control the quality of glutinous rice pulp, it is not considered suitable for large-scale application in practical engineering applications. The main component of glutinous rice pulp is starch, with the mass percentage of $75-77 \%$. Moreover, previous studies also indicated that the strengthening mechanism of glutinous rice pulp is mainly based on the regulation of amylopectin on calcium carbonate crystallization in glutinous rice pulp [45]. Starch ether is the product of starch etherification, the main component of which is starch. Starch ether is a widely used industrial product with large output and stable quality. Moreover, it has numerous advantages, 
such as low viscosity, high hydrophilicity, good fluidity, weak condensation, and high stability. Therefore, starch ether was selected to replace glutinous rice pulp as the restoration material of silty earthen sites in this study.

In the present study, traditional materials including lime and starch ether were used to modify silt in order to restore silty earthen site. Lime and starch ether were added to silt singly or together to prepare the modified soil samples, respectively. The direct shear test, compression tests, and durability test were carried out. Through comparative analysis of the engineering properties of modified soil and original site soil, the modification effect and mechanism of lime and starch ether on silt were analyzed, and the optimal content was determined.

\section{Test Materials and Methods}

2.1. Test Materials. The main materials used in the tests were silt, lime, and starch ether. Silt was collected from the periphery of the Tongwan City site. The site is located in Jingbian County, Northwest China, with a history of nearly 1600 years. Through sieving and adjusting soil particles, the test soil was prepared as similar as possible to the original site soil in gradation and physical properties. The particle gradation and physical index of the two types of soil are presented in Tables 1 and 2, respectively. The particle-size distribution curve of test soil is shown in Figure 1. Clearly, the physical indexes of original site soil and the test soil are, relatively, similar. In this study, all the tests were in accordance with the Standard for Soil Test Method [46].

The lime used in the test was ordinary building lime with uniform and delicate particles (Figure 2(a)). The physical indexes are summarized in Table 3. The hydroxypropyl starch ether used in the test is a white fine powder, produced by spray drying after natural etherification, which has good fluidity, water solubility, and stable viscosity (Figure 2(b)). Its physical indexes are presented in Table 4.

2.2. Preparation of Samples. Lime and starch ether were added to slit as single or double additives, respectively, to prepare the corresponding single-mixed modified soil samples and multiple-mixed modified soil samples.

2.2.1. Preparation of Site Soil Sample. In the tests, the site soil was sampled with ring knife. The area of ring knife was $30 \mathrm{~cm}^{2}$ and the height was $20 \mathrm{~mm}$.

\subsubsection{Preparation of Single-Mixed Modified Soil Samples.} In general, the volume ratio of lime to soil is $1: 9,2: 8$, and 3 : 7 in practical engineering applications and the corresponding mass percentage of lime is about 6,9 , and $12 \%$. Therefore, the mass percentages of lime used in the samples were selected as $0,3,6,9$, and $12 \%$, respectively. During sample preparation, lime was mixed proportionally with dried soil, and water was added to the set content. Starch ether was mixed with water to prepare solutions with concentrations of $0,5,10,15$, and $20 \%$, respectively. Then these solutions were mixed with soil and stirred evenly. The samples were prepared by static compaction; and the diameter and height of the so-obtained sample were 61.8 and $20 \mathrm{~mm}$, respectively. The dry density was $2.07 \mathrm{~g} \cdot \mathrm{cm}^{-3}$ and the water content was $6.55 \%$, which were similar to those of the original site soil. After the sample was prepared, it was sealed in a humidifying cylinder for 7,14 , and 28 days for experimental tests.

\subsubsection{Preparation of Multiple-Mixed Modified Soil Samples.} Based on the analysis and comparison of the single-mixed modified soil test results, the lime-soil mixtures with lime mass percentage of 6,9 , and $12 \%$ were prepared first, and then the starch ether solutions with concentrations of 5,10 , and $15 \%$ were added to the lime-soil mixtures to prepare multiple-mixed soil samples. The preparation method of the multiple-mixed soil samples was similar to that for singlemixed modified soil samples.

\subsection{Experimental Tests}

2.3.1. Direct Shear Test and Compression Test. The direct shear test and compression test were carried out on the single-mixed modified soil and multiple-mixed modified soil samples at different ages.

(1) Direct Shear Test. The experiment was carried out using a ZJ quadruple strain controlled direct shear apparatus. The test type was consolidation fast shear with the shear speed of $0.8 \mathrm{~mm} \cdot \mathrm{min}^{-1}$ and under the vertical loads of $100,200,300$, and $400 \mathrm{kPa}$, respectively.

(2) Compression Test. The compression test was performed using a WG single lever consolidation compression instrument. The loading sequence was $100,200,400,800$, and $1600 \mathrm{kPa}$. The load-holding time of each stage was $24 \mathrm{~h}$.

2.3.2. Environmental Durability Test. According to the results of mechanical tests of the single-mixed modified soil and multiple-mixed modified soil samples, the optimum samples were selected to carry out the environmental durability tests, including wear test, freeze-thaw test, and water stability test. Same tests were carried out on the original earthen site soil samples as well for comparative analysis. There are few test standards for environmental durability of earthen sites; therefore, the environmental durability test performed herein was based on the existing relevant or similar test method .

(1) Wear test

The natural environment of Tongwan City site is dry, windy, and sandy. As a famous historical site, many tourists visit this site every year and the contact between human and site is inevitable. Therefore, wind-sand erosion and contact wear are two important damage factors for the site. Figure 3 shows SCL-1 disintegration testing instrument, which was used to test the contact wear of soil samples. The self- 
TABle 1: Particle-size distribution of test soil.

\begin{tabular}{lccc}
\hline Particle-size distribution (\%) & & & \\
$>0.5 \mathrm{~mm}$ & $0.5-0.25 \mathrm{~mm}$ & $0.25-0.075 \mathrm{~mm}$ & $<0.075 \mathrm{~mm}$ \\
\hline 2.8 & 19.7 & 27.1 & 50.4 \\
\hline
\end{tabular}

TABle 2: Physical indexes of the original site soil and test soil.

\begin{tabular}{lccccc}
\hline Materials & & \multicolumn{2}{c}{ Indicators } \\
& Water content (\%) & Specific gravity (\%) & Liquid limit (\%) & Plastic limit (\%) & Plastic index \\
\hline Site soil & 6.55 & 2.65 & 14.2 & 9.5 & 4.7 \\
Test soil & 6.80 & 2.66 & 14.5 & 8.6 \\
\hline
\end{tabular}

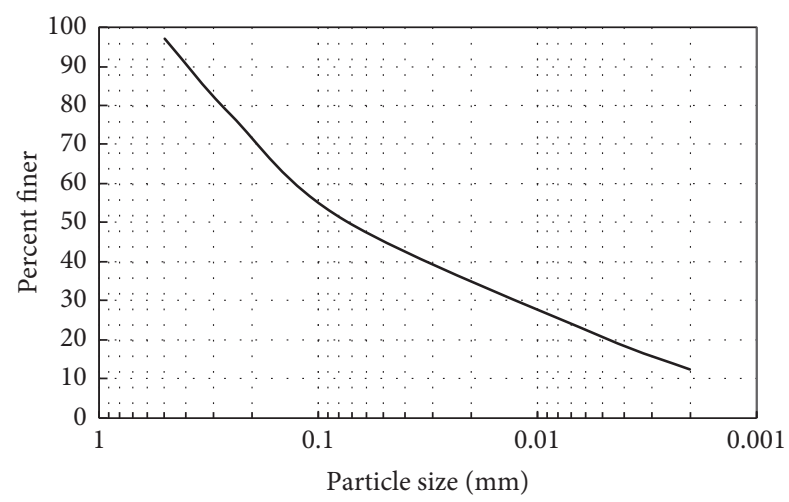

Figure 1: Particle-size distribution curve of test soil.

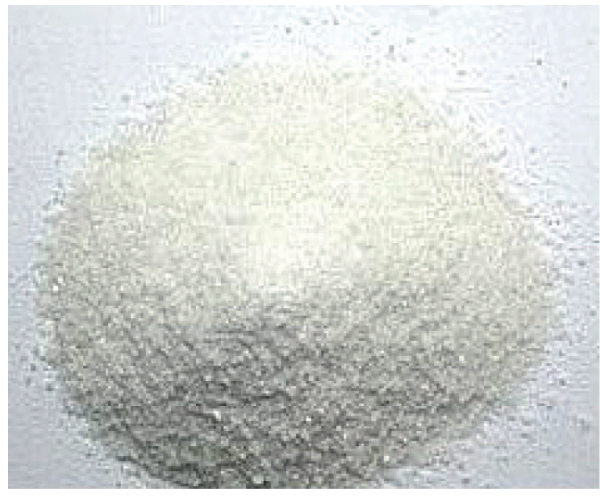

(a)

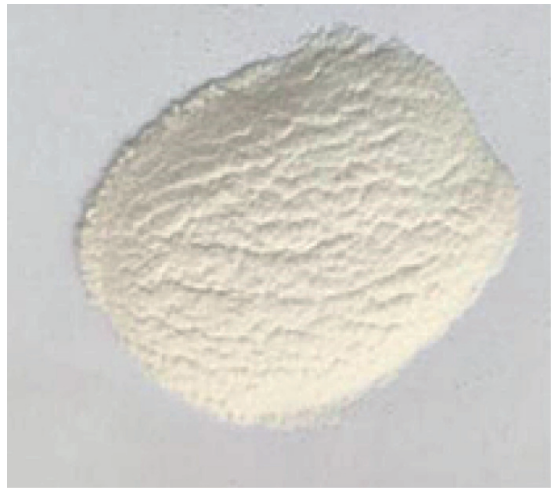

(b)

Figure 2: Test materials: (a) lime and (b) starch ether.

Table 3: Physical indexes of lime.

\begin{tabular}{lcccc}
\hline Appearance & Porosity $(\%)$ & $\mathrm{Ca}(\mathrm{OH})_{2}(\%)$ & Whiteness $(\%)$ & $\mathrm{CaO}(\%)$ \\
\hline 325 meshes residual screening $<0.5 \%$ & 32 & $>65$ & 90 & $>30$ \\
\hline
\end{tabular}

Table 4: Physical indexes of starch ethers.

\begin{tabular}{lccccc}
\hline Appearance & Solubility & Fineness $(\mu \mathrm{m})$ & $\mathrm{pH}$ & Viscosity $(\mathrm{mPa} \cdot \mathrm{s})$ & Water content $(\%)$ \\
\hline White powders & Dissolved in cold water & $\leq 500$ & $8-11$ & $>300$ & $<5 \%$ \\
\hline
\end{tabular}




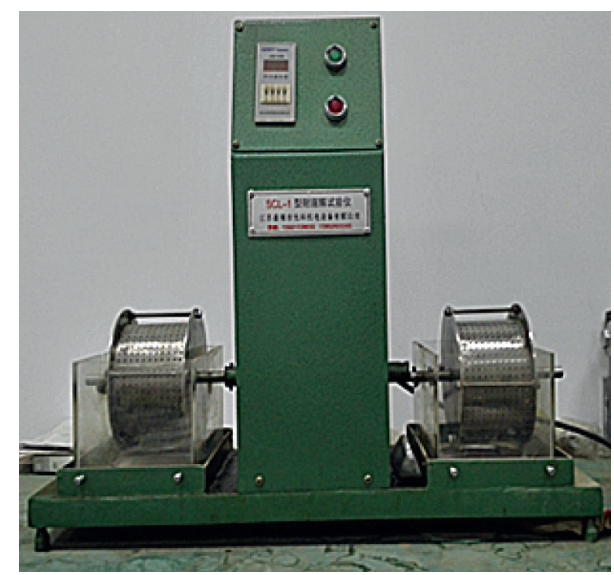

FIGURE 3: SCL-1 disintegration testing instrument.

made wind-sand blowing erosion device was used to test the wind-sand erosion of samples, which is shown in Figure 4.

SCL-1 disintegration test device is usually used to test the ability of rock to resist softening and disintegration. In this study, it was used to test the resistance of the site soil to contact wear under dry condition. Granular soil sample ( $30 \mathrm{~g})$ was prepared and placed into the instrument. When the rolling cage started to rotate, contact wear of the samples occurred. Each group of samples was tested five times, and each time lasted for $10 \mathrm{~min}$. After each test, the mass of the samples was measured and the wear ratio of the samples was obtained.

Figure 4 exhibits that the diagram of the self-made wind-sand blowing erosion device is mainly composed of wind source, sand supply system, blown erosion chamber, and sand collecting box. Under the conditions of sand supply ratio of $180 \mathrm{~g} \cdot \mathrm{min}^{-1}$ and wind speed of $25 \mathrm{~m} \cdot \mathrm{s}^{-1}$, the samples were blown for $20 \mathrm{~min}$. The mass loss ratio was obtained by weighing the mass of the samples before and after wind-sand erosion every $5 \mathrm{~min}$.

(2) Freeze-thaw cycles test

The main objective of this test was to study the influence of freezing and thawing on the soil and to obtain the variation ratio of the mass and volume of the samples. The test was carried out using an environment testing instrument, as shown in Figure 5.

The highest test temperature was $40^{\circ} \mathrm{C}$ and the lowest test temperature was $-20^{\circ} \mathrm{C}$. One test cycle started from high temperature to low temperature and then returned to high temperature. Each cycle lasted for $4 \mathrm{~h}$, and the total number of cycles was 30 . The samples were made into cubes with side length of $5 \mathrm{~cm}$. The variation ratios of mass and volume of the samples were measured after every 10 cycles.

(3) Immersion stability test

The surface of the earthen site gets easily eroded due to rainwater, which can cause damage of pits and gullies. In this study, the samples of modified soil and site soil were soaked in water, respectively, and immersion stability of different soils was compared by observing the disintegration degree of soil in water.

\section{Test Results and Discussion}

3.1. Test of Single-Mixed Modified Soil. The lime or starch ether was added to the soil individually to prepare the singlemixed modified soil samples for the test.

3.1.1. Direct Shear Test. For samples with different extent of ageing, the relationship curves of shear parameters with lime content and concentration of starch ether solution are shown in Figures 6 and 7.

The test results showed that the shear strength parameters of samples could be improved by adding lime or starch ether individually. Regarding samples age, the cohesion $c$ and internal friction angle $\varphi$ of the modified soils showed significant increase during the period of 7 to 14 days, and the increases of $c$ and $\varphi$ were relatively small during the period of 14 to 28 days. Therefore, it was concluded that $c$ and $\varphi$ of the modified soil increased sufficiently after 14 days age. When the lime content was $9 \%$ and age was 28 days, the cohesion and internal friction angle of lime-modified soil reached maximum values of $72.45 \mathrm{kPa}$ and $48.6^{\circ}$, respectively. When the starch ether concentration was 5\% and age was 28 days, the cohesion and internal friction angle of starch ethermodified soil reached maximum values of $80.32 \mathrm{kPa}$ and $42.3^{\circ}$, respectively. The maximum cohesion of starch ethermodified soil was higher than that of lime modified-soil, while the maximum internal friction angle was smaller than that of lime-modified soil.

Lime is the earliest and the most widely used cementitious material, and use of lime to modify soil is a common engineering method [47-49]. The test results indicated the significant improvement in the strength of soil due to the addition of lime, which is closely related to the ion exchange, pozzolanic reaction, and carbonation reaction of lime and soil. Ion exchange refers to the exchange of $\mathrm{Ca}^{2+}$ cations in lime and $\mathrm{Na}^{+}$and $\mathrm{K}^{+}$cations in soil, which can reduce the surface potential of soil particles, lead to the thinning of the adsorption layer, and increase the attraction between molecules. Thus, the soil particles are closely combined to improve the strength and stability of lime soil. Ion exchange is the main factor that promotes the early strength of lime soil. The pozzolanic reaction refers to the reaction between $\mathrm{NaOH}$ in lime and active silicon/aluminum oxides in soil. Hydrated calcium silicate gel and calcium aluminate hydrate crystals filled pores during the reaction. This reduced the void volume between the soil particles, reduced the permeability, and increased the density of the soil. The pozzolanic reaction is very helpful to improve the early and later compressive strength of lime-improved soil. Carbonation refers to the reaction of $\mathrm{Ca}(\mathrm{OH})_{2}$ in lime soil with $\mathrm{CO}_{2}$ in the air to produce $\mathrm{CaCO}_{3}$. Notably, $\mathrm{CaCO}_{3}$ has good strength and water stability, and its solid volume is larger than that of 


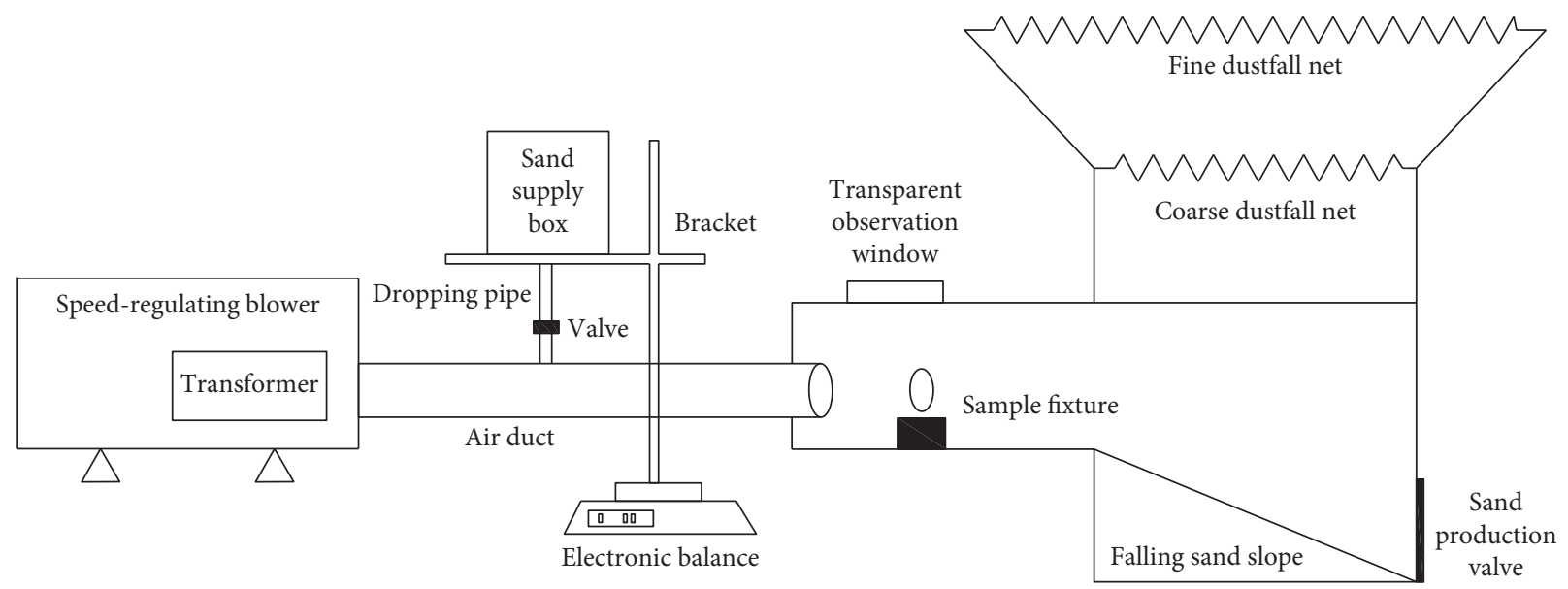

FIgURE 4: The diagram of wind-sand blowing erosion device.

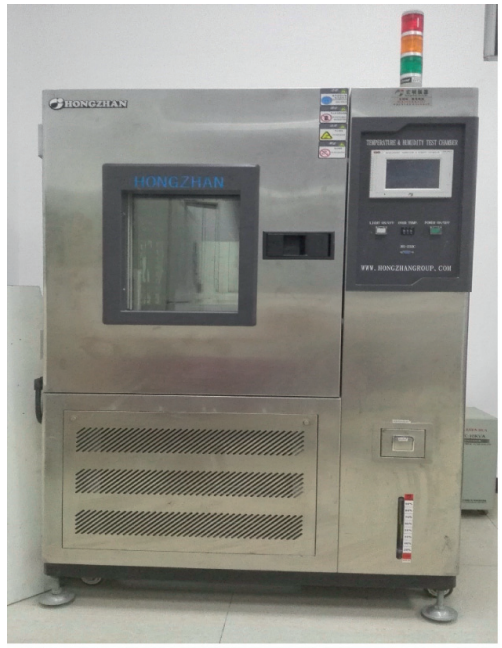

FIGURE 5: The environment testing instrument.

$\mathrm{Ca}(\mathrm{OH})_{2}$. This was found to be helpful to improve the compactness and stability of lime soil. Carbonation is a long process, and it is a main factor to improve the strength of lime soil in the later stage.

According to the test data, the reactions in lime soil were developed rapidly in the early stage, and reaction was relatively sufficient when the age reached 14 days. Further, the reaction speed slowed down. Moreover, when lime content was less than $9 \%$, with the increase of lime content, the gel substances increased. Therefore, the connection of soil particles became stronger, the structure of soil became denser, and the strength of soil was enhanced due to the addition of lime. When the content of lime was more than $9 \%$, the excessive $\mathrm{NaOH}$ crystal adhered to the surrounding of the soil particles, which hindered the connection between the soil particles, resulting in loose structure of lime soil and reduction of the strength. Therefore, the cohesion and internal friction angle of lime modified-soil increased when the lime content was less than $9 \%$ and decreased slightly when the lime content was more than $9 \%$.

Starch ether is a type of modified starch with ether bond, which is also called etherified starch. Starch acquires certain viscosity after gelatinization. Etherified starch exhibits better viscosity and stability, and it is widely used in mortar construction, food, textile, and other fields. Addition of starch ether results in sticking together of the soil particles, which leads to the effective improvement in the shear strength of soil. Some scholars have also found that the slip resistance performance of the mortar gets significantly improved by adding starch ether $[50,51]$, which is similar to the experimental results presented in this study to a certain extent. Therefore, starch ether can enhance the cohesive force between the soil particles, which is helpful to resist shear slip.

When the concentration of starch ether solution was less than $5 \%$, the bonding effect was found to be good and the strength of soil increased. However, when the concentration of starch ether solution was more than $5 \%$, excessive starch ether solution became the lubricant between soil particles, which reduced the ability of the soil to resist shear. Therefore, the cohesion and internal friction angle of starchether-modified soil increased when the concentration of starch ether solution was less than $5 \%$ and decreased when the lime content was more than $5 \%$. With respect to the addition of lime or starch ether, the optimum proportion should be selected in the actual project to obtain the best performance.

3.1.2. Compression Test. Considering that the shear strength parameters of lime- or starch-ether-modified soil tend to get stabilized after 28 days, the samples with 28-day age were selected for compression tests. The curves of variation of compression parameters with content of lime and starch ether are presented in Figures 8 and 9, respectively.

The compression coefficient $a_{1-2}$ corresponds to the vertical pressure in the range of $100-200 \mathrm{kPa}$, and the compression index $C_{c}$ value corresponds to the slope of the nearly straight section of the compression curve in the $e-\log p$ coordinate.

The test results clearly revealed that, with the increase of lime content, the compression coefficient and compression index of samples were basically reduced. When the lime 


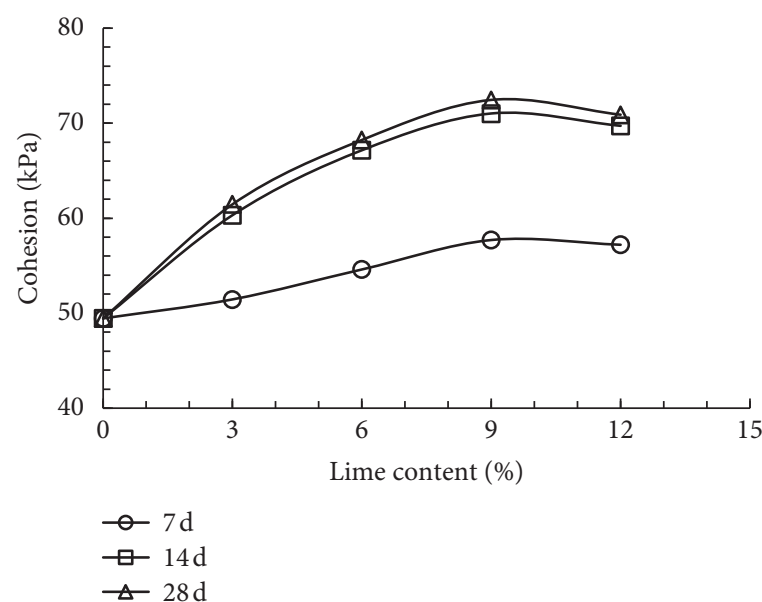

(a)

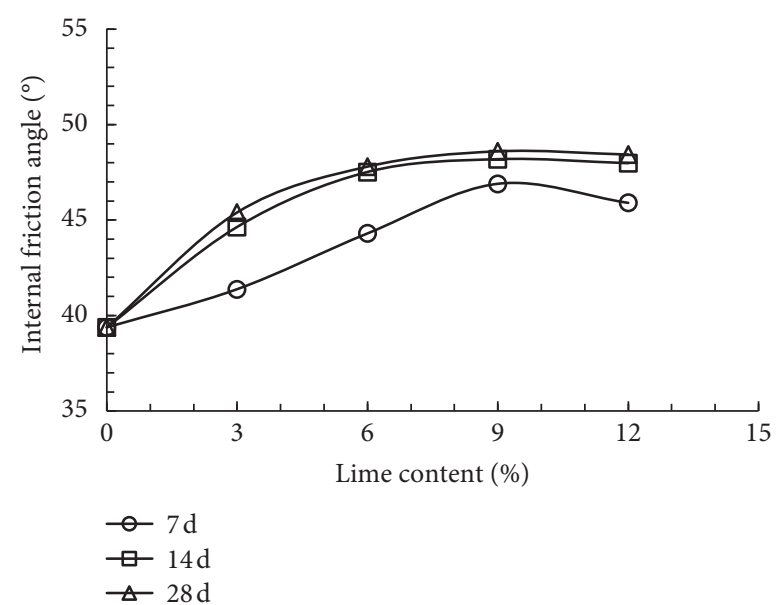

(b)

FIGURE 6: The relationship between shear strength parameters and lime content. (a) The relationship between cohesion and lime content. (b) The relationship between internal friction angle and lime content.

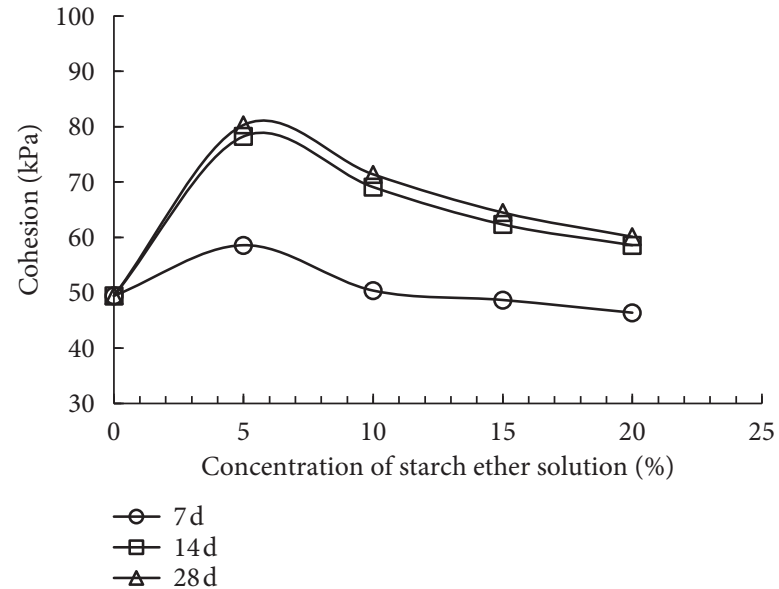

(a)

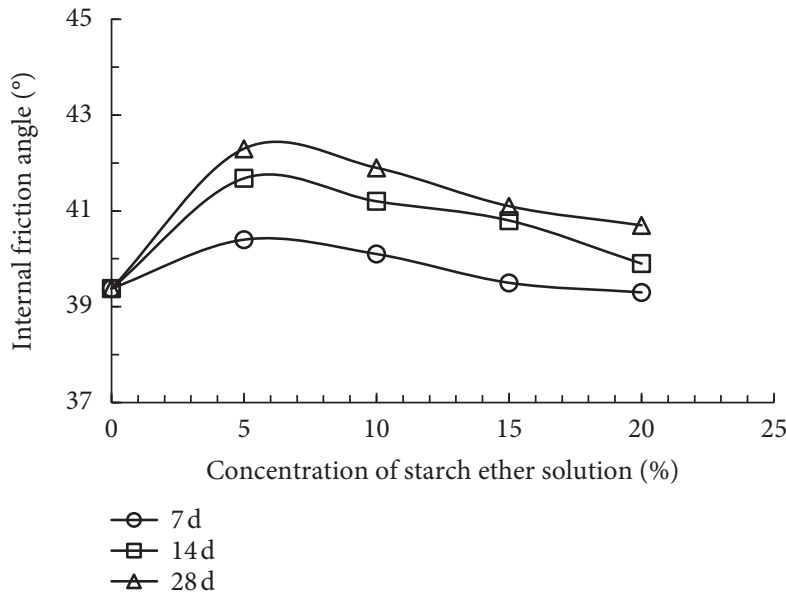

(b)

Figure 7: The relationship between shear strength parameters and concentration of starch ether solution. (a) The relationship between cohesion and concentration of starch ether solution. (b) The relationship between internal friction angle and concentration of starch ether solution.

content was $9 \%$, the compression coefficient and compression index of lime-modified soil reached the minimum values, $0.037 \mathrm{MPa}^{-1}$ and 0.0124 , respectively. However, with the increase of starch ether concentration, the compression coefficient and compression index of the samples first decreased and then increased. The compression coefficient reached the minimum value of $0.056 \mathrm{MPa}^{-1}$, when the concentration of starch ether solution was 5\%. Moreover, the compression index reached the minimum value of 0.0266 , when the concentration of starch ether solution was $10 \%$. The compressibility coefficient and compression index of lime-modified soil were lower than those of starch-ether-modified soil. The mechanism explanation of consolidated compression test results is similar to that of direct shear test results.
3.2. Test of Multiple-Mixed Modified Soil. The starch ether solution with different concentrations of 5,10 , and $15 \%$ was added to the lime soils with lime content of 6,9 , and $12 \%$, respectively, in order to prepare the multiple-mixed modified soil samples for direct shear and compression tests. The results are as follows.

3.2.1. Direct Shear Test. After adding starch ether solutions with different concentrations, respectively, to lime soil with 6, 9, and $12 \%$ lime content, the direct shear tests were performed on multiple-mixed modified soil samples and the corresponding results are shown in Figures 10-12, respectively. 


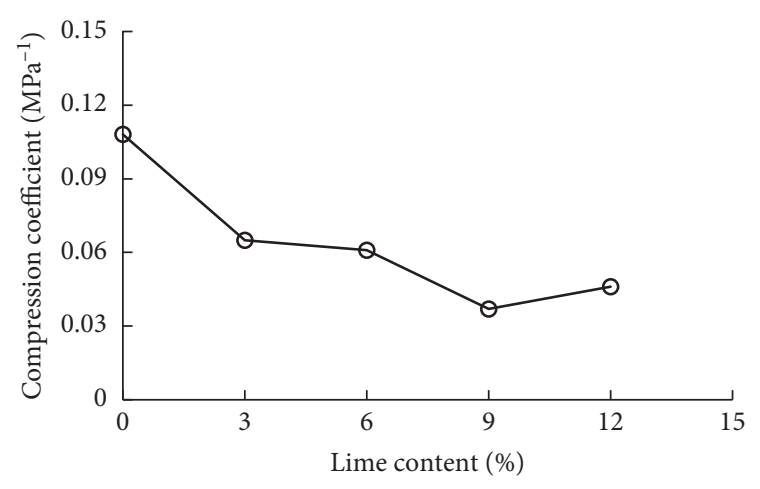

(a)

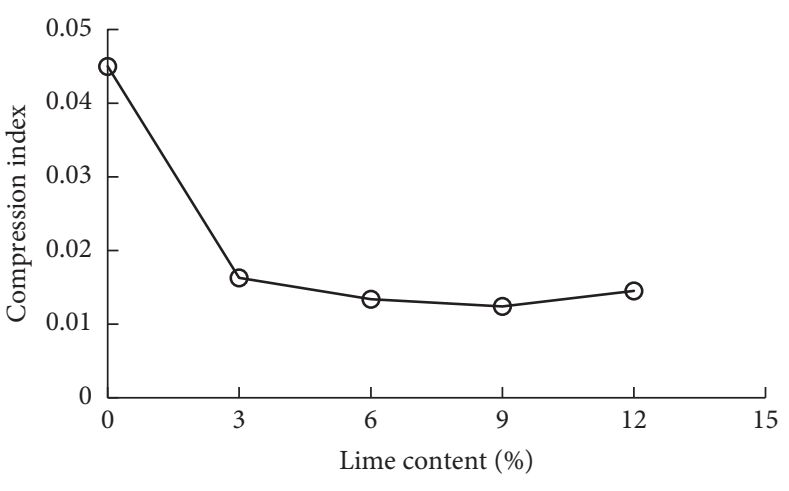

(b)

FiguRE 8: The relationship between compression parameters and lime content. (a) The relationship between compression coefficient and lime content. (b) The relationship between compression index and lime content.

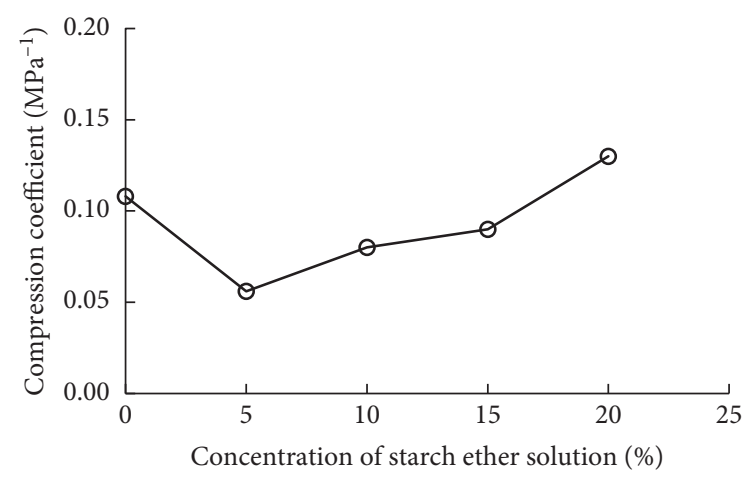

(a)

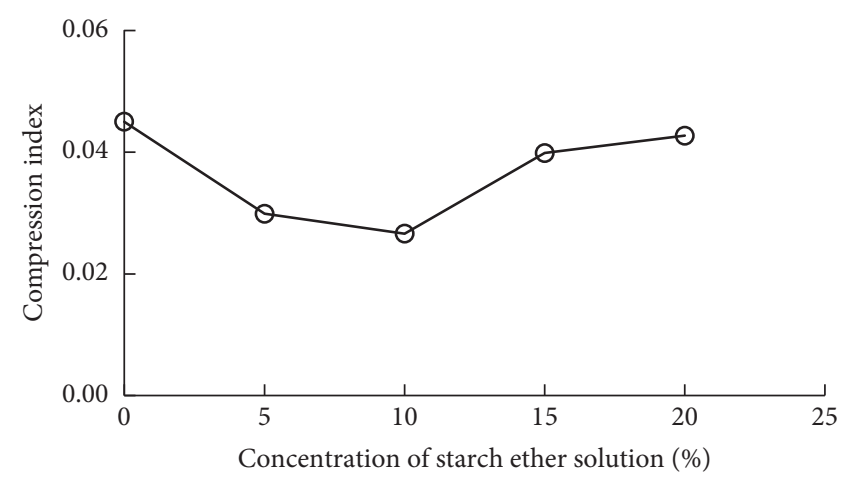

(b)

Figure 9: The relationship between compression parameters and concentration of starch ether solution. (a) The relationship between compression coefficient and starch ether concentration. (b) The relationship between compression index and starch ether concentration.

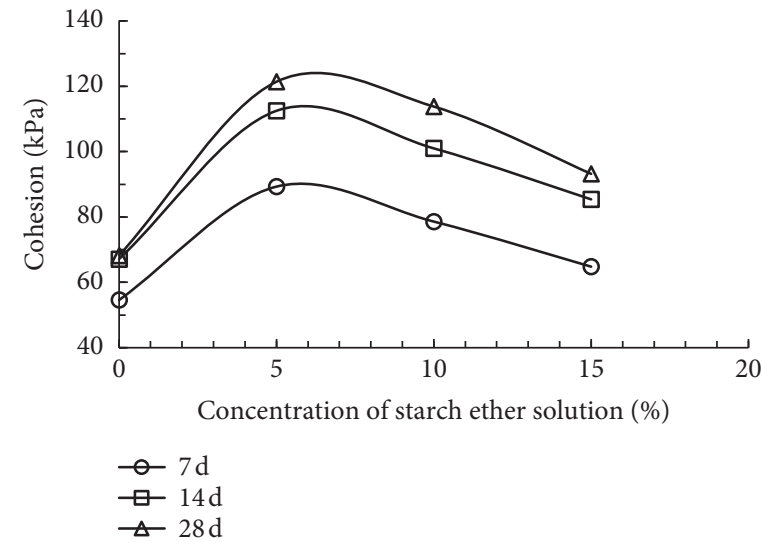

(a)

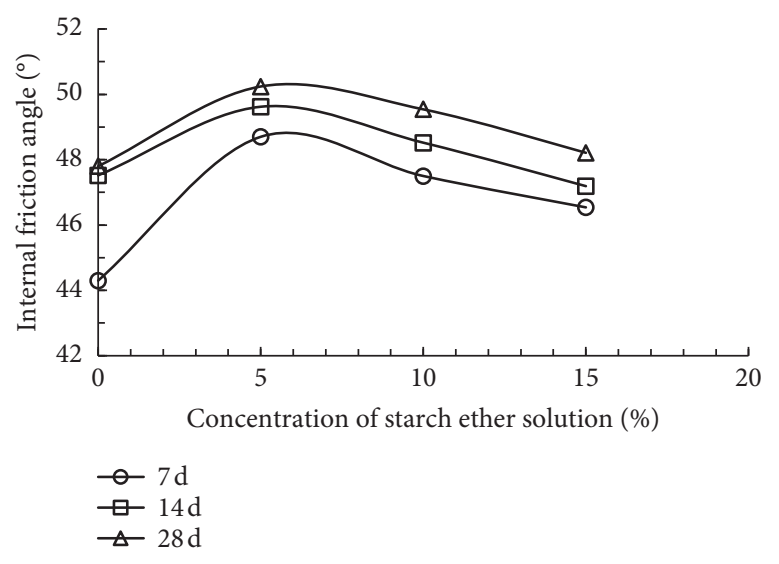

(b)

FIGURE 10: The relationship between shear strength parameters and concentration of starch ether solution (lime content: 6\%). (a) The relationship between cohesion and starch ether concentration. (b) The relationship between internal friction angle and starch ether concentration.

Test results showed that the influence of curing age on multiple-mixed modified soil sample was found to be similar to that on single-mixed modified soil sample. After starch ether was added to lime soil, the cohesion and internal friction angle of multiple-mixed modified soil were generally higher than those of single-mixed modified soil containing same content of lime. 


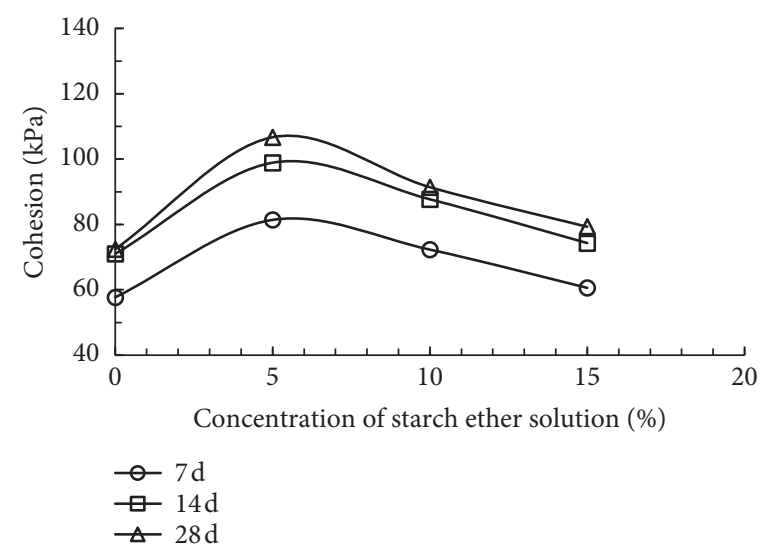

(a)

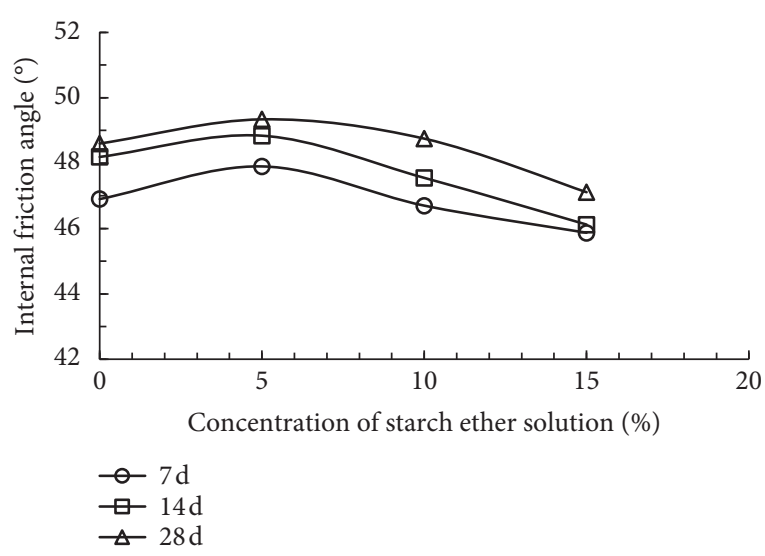

(b)

Figure 11: The relationship between shear strength parameters and concentration of starch ether solution (lime content: 9\%). (a) The relationship between cohesion and starch ether concentration. (b) The relationship between internal friction angle and starch ether concentration.

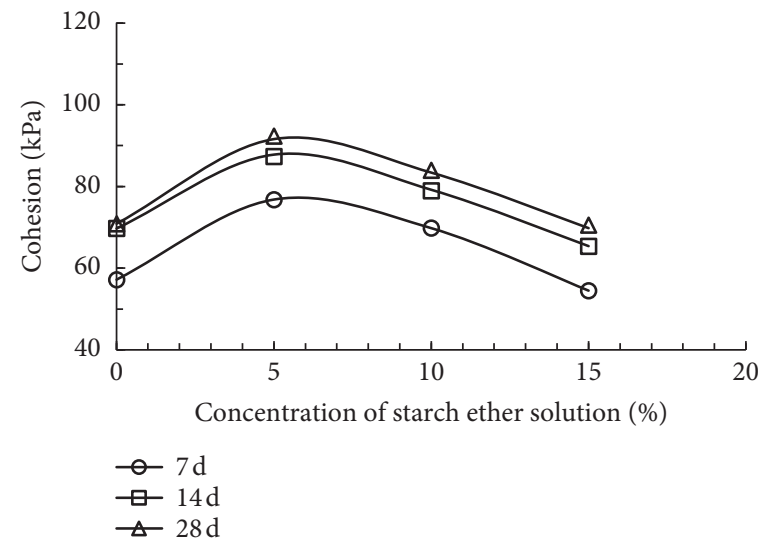

(a)

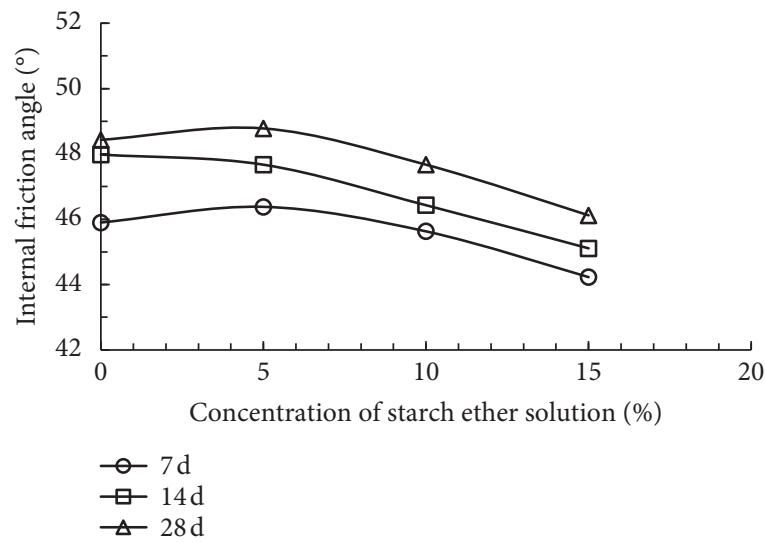

(b)

Figure 12: The relationship between shear strength parameters and concentration of starch ether solution (lime content: 12\%). (a) The relationship between cohesion and starch ether concentration. (b) The relationship between internal friction angle and starch ether concentration.

With the increase of starch ether concentration, the cohesion and internal friction angle of multiple-mixed modified soil first increased and then decreased. When the concentration of starch ether solution was $5 \%$, the cohesion and internal friction angle of multiple-mixed soil reached the maximum values. Noteworthy, when the lime content was $6 \%$ and the starch ether concentration was $5 \%$, the cohesion and internal friction angle of the multiple-mixed soil reached the maximum values, $121.4 \mathrm{kPa}$ and $50.24^{\circ}$, respectively. The maximum values of cohesion and internal friction angle of the multiple-mixed modified soil were 67.6 and $3.37 \%$ higher than those of the lime-modified soil and were 51.1 and $18.8 \%$ higher than those of the starch-ethermodified soil, respectively.

For the comprehensive and visual understanding of the relationship between shear strength parameters, starch ether solution concentration, and lime content, the relationship between cohesion, concentration of starch ether solution, and lime content under different ages is shown in Figure 13, and the relationship between internal friction angle, concentration of starch ether solution, and lime content under different ages is shown in Figure 14. Figures 13 and 14 show that the cohesion and internal friction angle of the modified soil increase with the age and reach the maximum value, when the concentration of starch ether solution is $5 \%$ and the content of lime is $6 \%$. Comparative analysis of Figures 13 and 14 indicate that the change of internal friction angle is smaller, while the change of cohesion is larger, which reveals that starch ether and lime exhibit more significant influence on cohesion of multiple-mixed soil.

For the comprehensive and visual understanding of the relationship between shear strength parameters, starch ether solution concentration, and lime content, the relationship between cohesion, concentration of starch ether solution, 

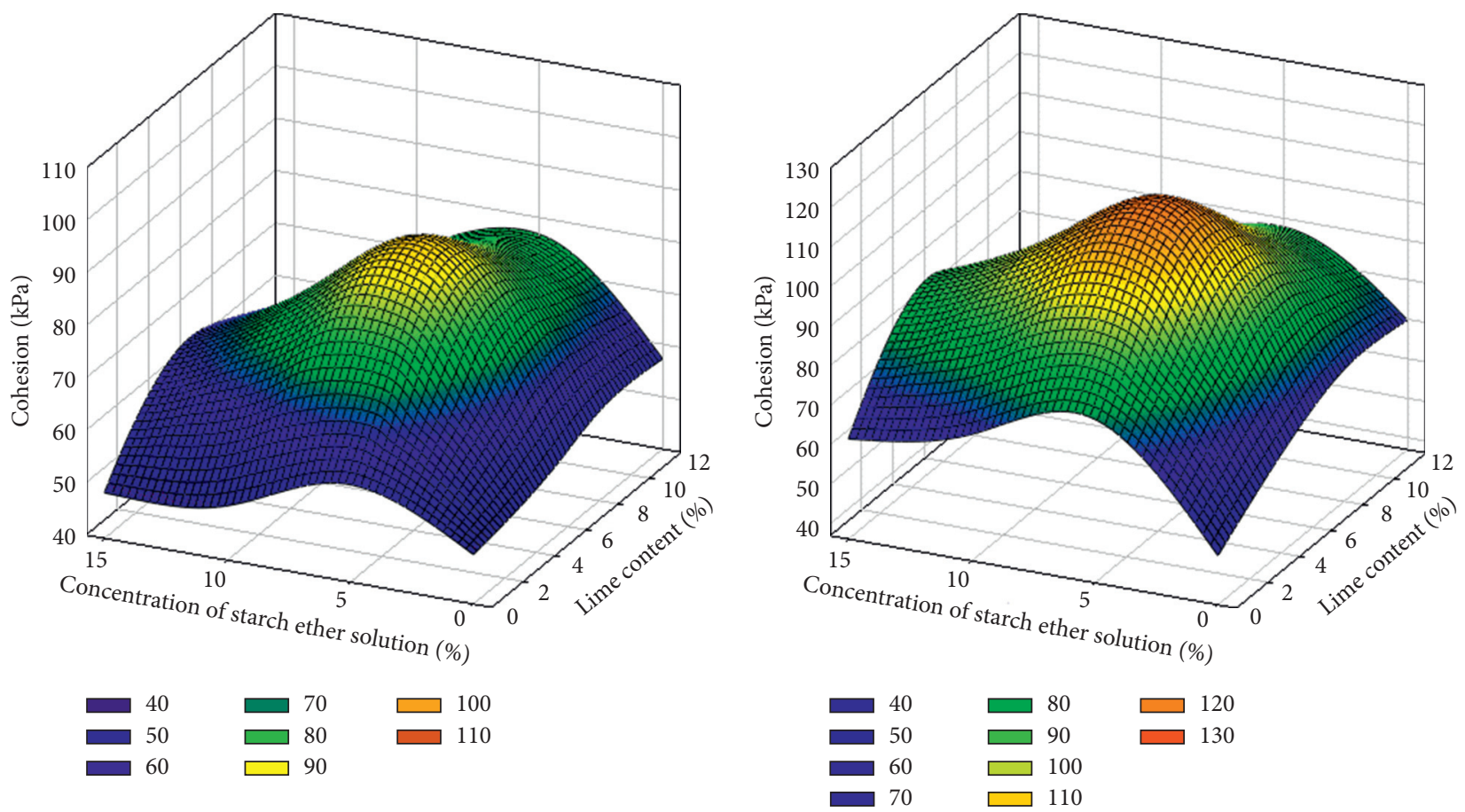

(a)

(b)

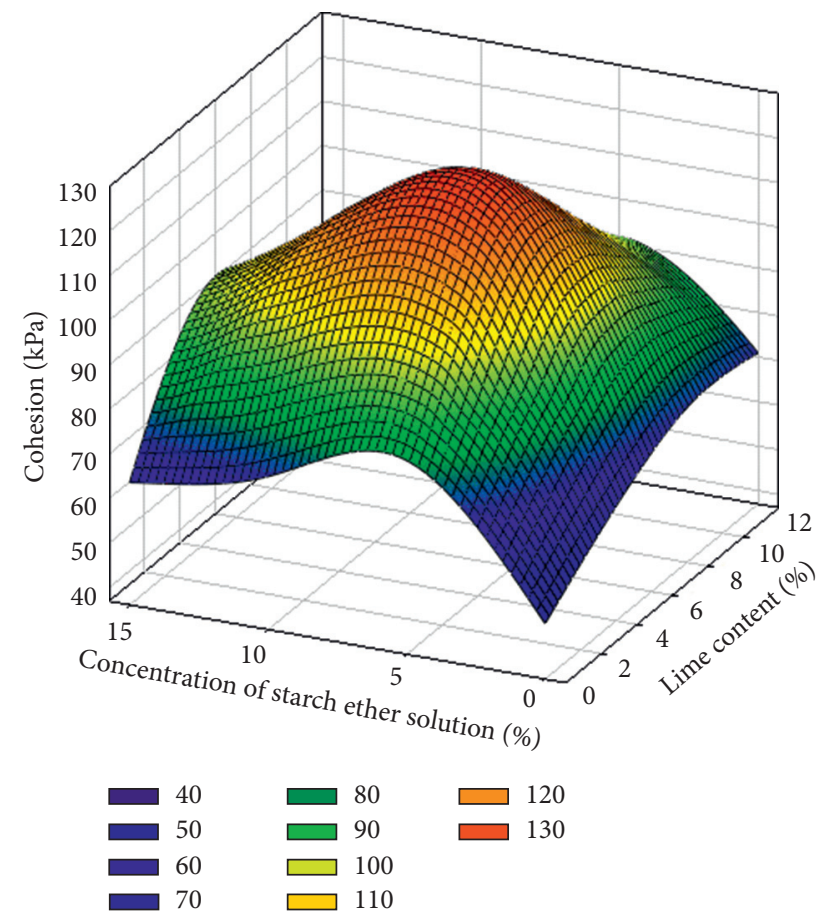

(c)

FIGURE 13: The relationship of cohesion, concentration of starch ether solution, and lime content under different ages: (a) $7 \mathrm{~d}$ age, (b) $14 \mathrm{~d}$ age, and (c) $28 \mathrm{~d}$ age.

and lime content under different ages is shown in Figure 13, and the relationship between internal friction angle, concentration of starch ether solution, and lime content under different ages is shown in Figure 14.

Figures 13 and 14 show that the cohesion and internal friction angle of the modified soil increase with the age and reach the maximum value, when the concentration of starch ether solution is $5 \%$ and the content of lime is $6 \%$. Comparative analysis of Figures 13 and 14 indicates that the change of internal friction angle is smaller, while the change of cohesion is larger, which reveals that starch ether and lime exhibit more significant influence on cohesion of multiple-mixed soil. 

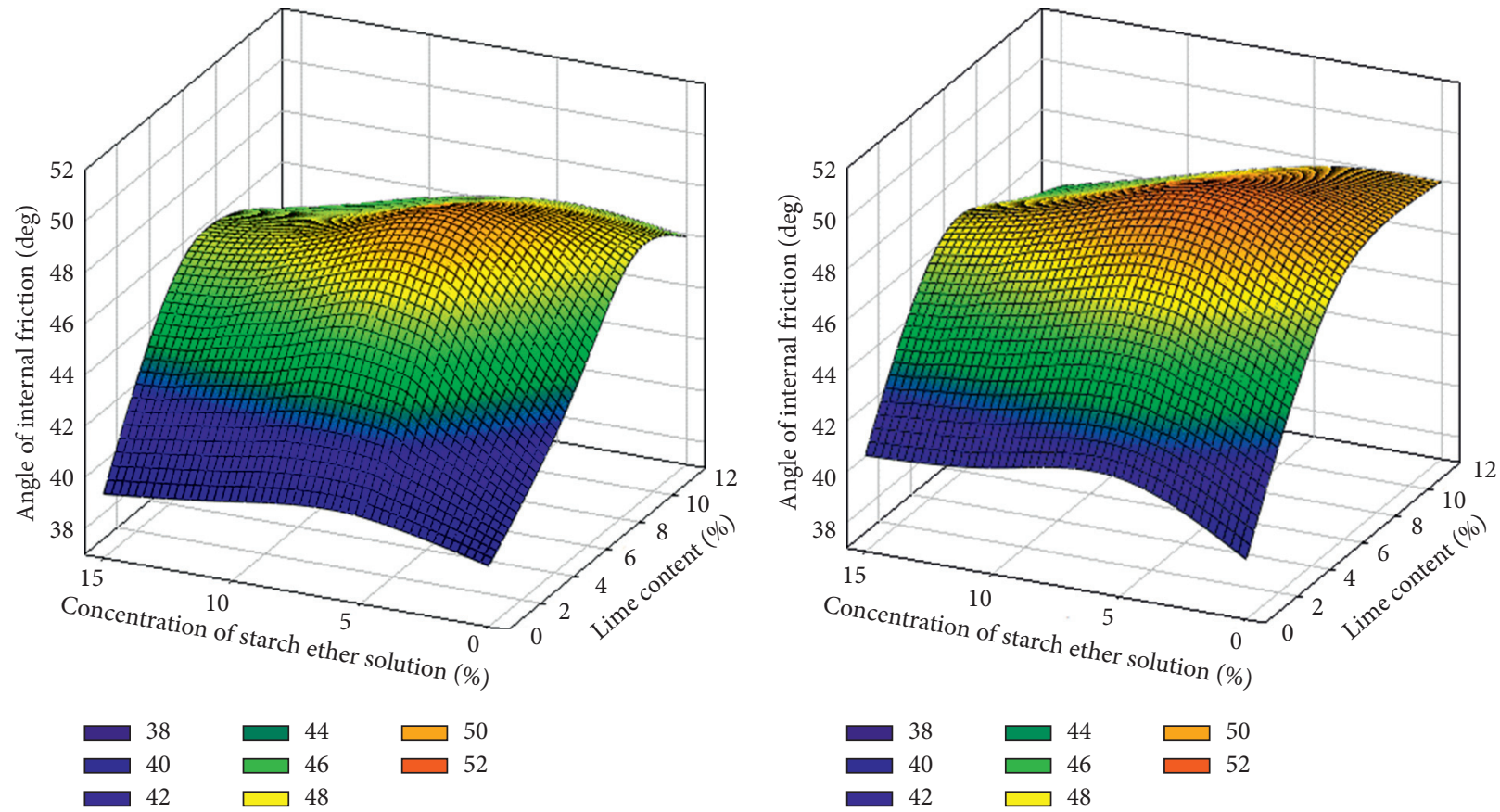

(a)

(b)

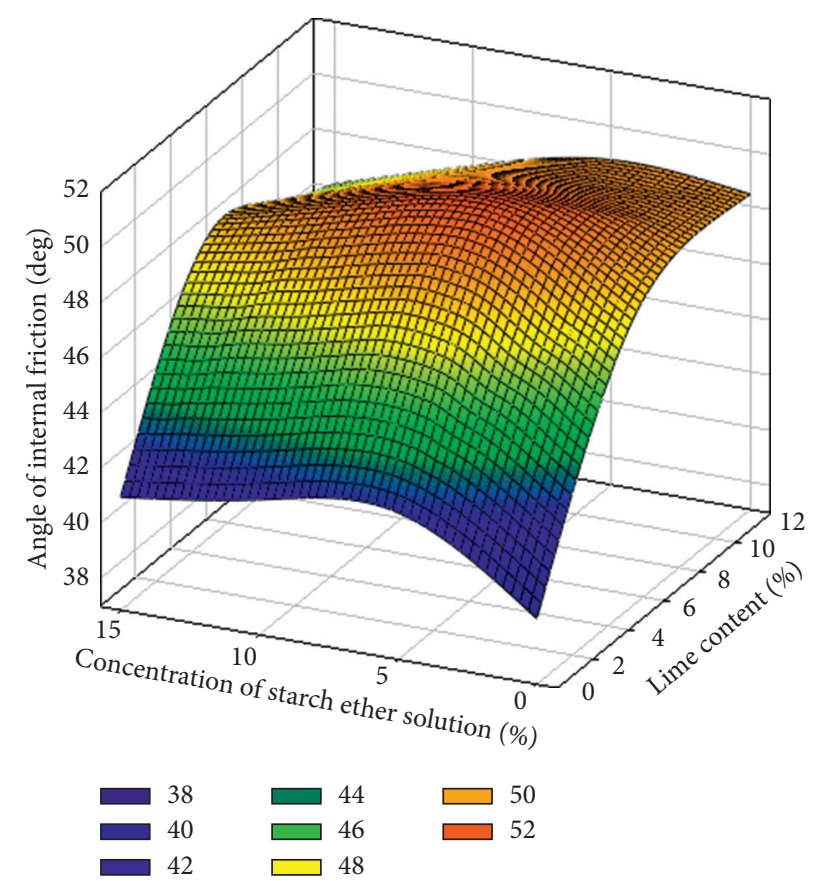

(c)

FIGURE 14: The relationship of internal friction angle, concentration of starch ether solution, and lime content under different ages: (a) $7 \mathrm{~d}$ age, (b) $14 \mathrm{~d}$ age, and (c) $28 \mathrm{~d}$ age.

In multiple-mixed modified soil, when lime reacts with soil, starch ether also binds particles. Under such double effect, the strength of multiple-mixed modified soil becomes higher than that of single-mixed soil. The water contents in multiple-mixed and single-mixed soil are the same. The comparative analysis indicates that, in single-mixed modified soil, water reacts with lime or starch ether alone. In contrast, in multiple-mixed modified soil, the same amount of water is required to interact with both lime and starch ether at the same time, which may lead to insufficient reaction. As a result, the strengthening effect of lime and starch ether on multiple-mixed modified soil is not as much as that on single-mixed soil. Therefore, although the strength of multiple-mixed modified soil is higher, its value is not the simple summation of the strength of lime-modified soil and starch-ether modified soil but is lower than this summation. 
Moreover, the optimal lime content of the single-mixed soil was $9 \%$, while the optimal lime content of the multiplemixed soil was decreased to $6 \%$. Starch ether has better water absorption and retention properties; thus the actual reaction of water with lime in the multiple-mixed soil is relatively less, which leads to the increase in the content of unreacted lime, resulting in the decrease of soil strength. Therefore, in the multiple-mixed soil sample, the optimal content of lime gets reduced.

3.2.2. Compression Test. The compression test results of the samples with 6, 9, and $12 \%$ lime content with different concentrations of added starch ether solution are shown in Figure 15, respectively.

When the concentration of starch ether solution was $5 \%$, the compression coefficient and compression index of modified soil containing different lime contents were generally close to the minimum value. Noteworthy, when the concentration of starch ether solution was less than $5 \%$, the content of lime exhibited significant influence on the compression coefficient and compression index of multiplemixed modified soil. In contrast, when the concentration of starch ether solution was more than $5 \%$, the effect of lime content on the compressibility of soil was not significant. The mechanism explanation of compression test results is also similar to that of direct shear test results.

Therefore, for multiple-mixed modified soil, when the lime content was $6 \%$ and the starch ether concentration was $5 \%$, the shear strength reached the maximum value and the compressibility acquired the minimum value. Compared to those of single-mixed modified soil, the engineering properties of multiple-mixed modified soil were significantly improved.

\subsection{Comparative Analysis of Optimum Modified Soil and} Original Site Soil. Most earthen sites are generally exposed to the natural environment; thus, environmental factors have significant impact on the integrity and safety of these earthen sites. Therefore, in addition to mechanical properties, environmental durability should also be an important characteristic of restoration materials for earthen sites. According to the above-mentioned test results, the modified soil can obtain better mechanical properties after adding 5\% starch ether solution and 6\% lime. Therefore, this type of multiple-mixed modified soil was selected as the optimum material for environmental durability testing. The engineering properties of this optimum modified soil were comprehensively compared with those of the original site soil to verify its suitability and feasibility as a restoration material for earthen sites.

3.3.1. Comparison of Shear Strength and Compressibility Index. Table 5 summarizes the comparison between shear strength and compressibility index for original site soil and optimum modified soil. The strength and compressibility indexes of the optimum modified-soil samples are similar to or slightly better than those of the original site soil samples.
Therefore, from the aspect of mechanical properties, it is feasible to use modified soil as an effective restoration material for earthen sites.

3.3.2. Wear Test. The test results of original site soil and modified soil in contact wear test and wind-sand erosion test are shown in Figures 16 and 17.

The results indicated that the mass loss ratio of modified soil was larger than that of original site soil. In the contact wear test, the difference of test results between two types of samples was relatively small; however, in the wind-sand erosion test, this difference was significant. The reaction between lime and soil is a long-term process. Although the strength of the modified soil increased rapidly in the early stage and slowly in the later stage, the age of modified soil was only 28 days. Considering that the original site soil has existed for thousands of years, the cumulative growth value of the soil strength and structure in the later stage cannot be ignored altogether in such a long time. Therefore, the mass loss ratio of original site soil was found to be relatively small, which is likely to be related to the short age and insufficient soil structure of the modified soil. Thus, herein, the more comprehensive reason requires further in-depth investigation in the future.

3.3.3. The Results of Freeze-Thaw Cycles Test. Table 6 presents the test results of freeze-thaw cycles of original site soil and optimum multiple-mixed modified soil. Table 6 summarizes that both the mass and volume of site soil and modified soil decreased after freeze-thaw cycles test. After lime and soil are mixed, lime exerts obvious cementation effect on soil particles. The denser the soil is, the smaller the pores become, the more limited the migration and accumulation of water are, and the weaker the damage due to freeze-thaw cycle on the soil is. The test values between site soil and modified soil are small and similar, which indicate that the two types of soil samples are insensitive to temperature change, and this result is mainly attributed to the low water content of the soil.

\subsubsection{Comparative Analysis of Water Immersion Stability.} Water is an important factor to investigate the damage of earthen sites. Therefore, immersion stability is another necessary property to be considered for restoration materials for earthen sites. After $30 \mathrm{~min}$ of water immersion, the disintegration degree of the original site soil and modified soil was obtained as shown in Figure 18.

Clearly, after water immersion, the site soil sample disintegrates seriously; nonetheless, the modified soil sample hardly disintegrates. Calcium hydroxide in lime of modified soil crystallizes after absorbing water to form crystal lattice structure. The formed crystals get easily combined with each other and can be combined with soil particles to form eutectic. In this way, the soil particles are cemented as a whole. Compared to the non-crystallinity of calcium hydroxide, the solubility of calcium hydroxide crystal is almost reduced by half, thus improving the water stability of modified soil. 


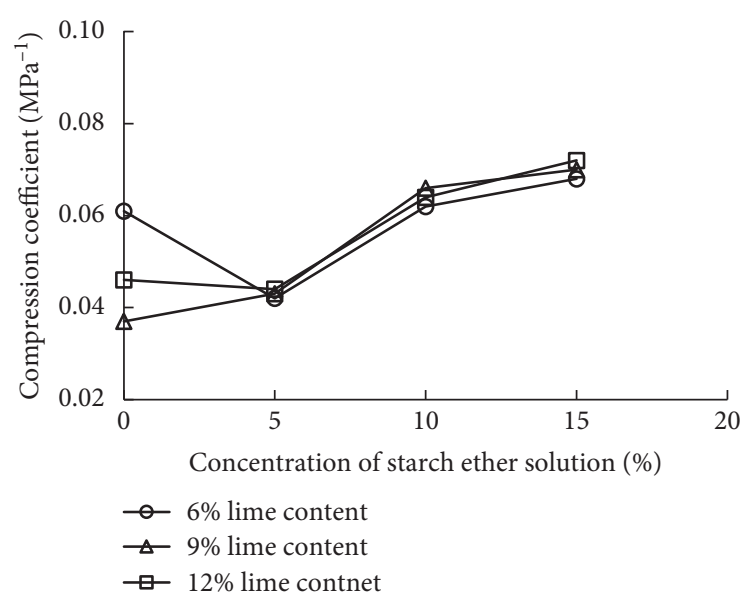

(a)

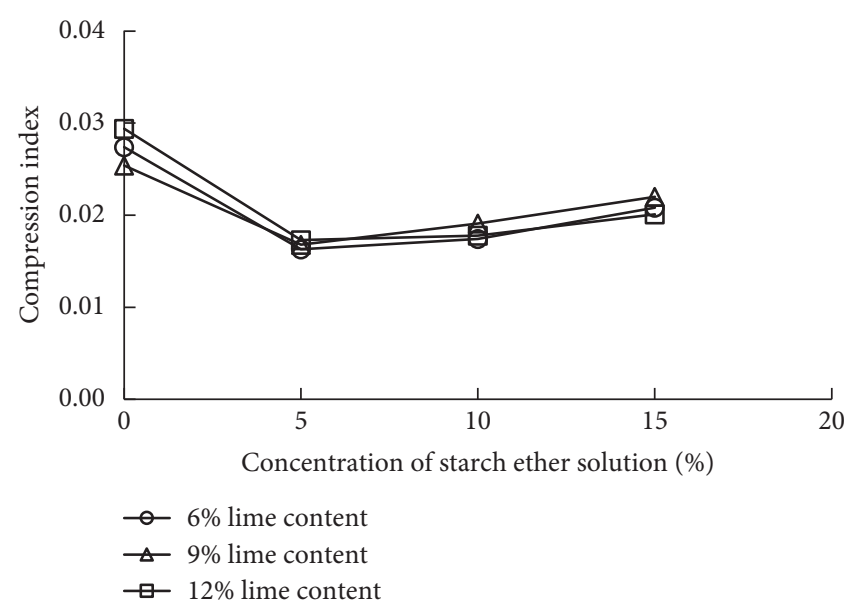

(b)

FIGURE 15: The relationship between compression parameters and starch ether concentration of multiple-mixed modified soil with different lime content. (a) The relationship between compression coefficient and starch ether concentration. (b) The relationship between compression index and starch ether concentration.

TABLE 5: Shear strength and compressibility indexes of original site soil and modified soil.

\begin{tabular}{lcccc}
\hline Sample & & & Parameter & \\
& Cohesion $(\mathrm{kPa})$ & Internal friction angle $\left(^{\circ}\right)$ & Compressibility coefficient $\left(\mathrm{MPa}^{-1}\right)$ & $\mathrm{Compression} \mathrm{index}^{\text {Con }}$ \\
\hline Site soil & 110.07 & 40.51 & 0.072 & 0.078 \\
Modified soil & 121.40 & 50.24 & 0.042 & 0.016 \\
\hline
\end{tabular}

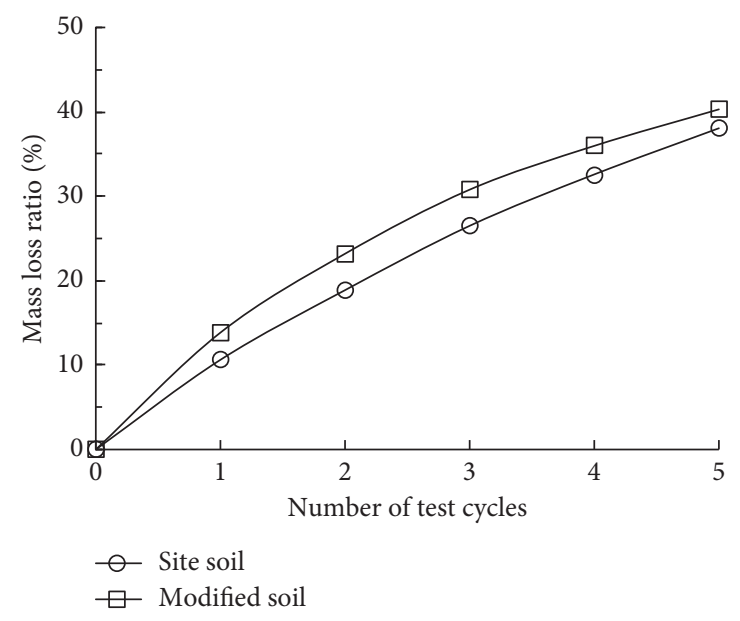

FIGURE 16: The results of contact wear test.

Moreover, noteworthy, the $\mathrm{pH}$ of the original test soil is 7.9, which belongs to alkaline soil. Lime and starch ether are basic materials; thus, the $\mathrm{pH}$ of modified soil increases to 9.3. In general, when the $\mathrm{pH}$ of soil is greater than 9.0, it is not suitable for the plants to grow. Therefore, the strong alkalinity of modified soil can avoid the damage caused due to plant growth, which is beneficial to the restoration and protection of earthen sites.
Importantly, economy is another factor to be considered in practical engineering. Lime and starch ether are widely used materials because of their cost-effectiveness. It is estimated that, by using $6 \%$ lime and $5 \%$ starch ether to modify silt, the cost of each ton of modified soil increases by only 54.27 RMB, equivalent to 7.75 US dollars. Therefore, the material selected in this study also has good economic value. 


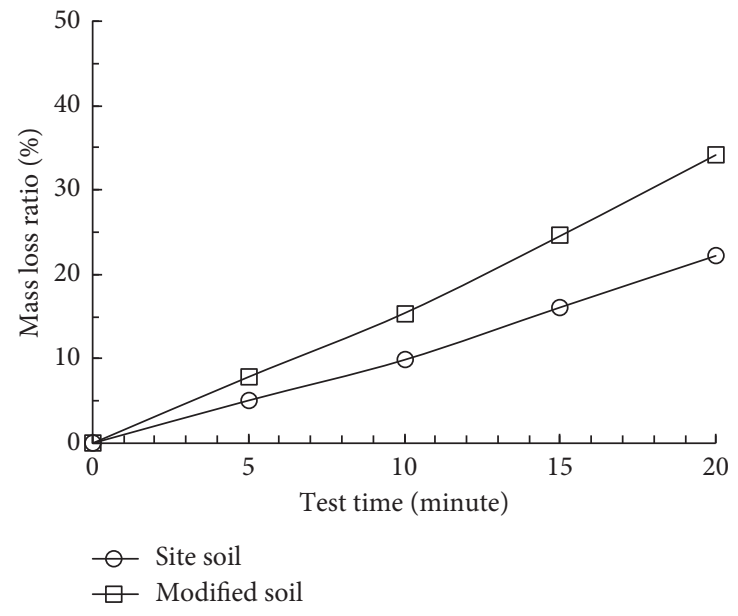

FIGURE 17: The results of wind-sand erosion test.

TABle 6: Freeze-thaw cycles test results of original site soil and modified soil.

\begin{tabular}{lccrr}
\hline \multirow{2}{*}{ Indicators } & \multirow{2}{*}{ Sample } & \multicolumn{3}{c}{ Number of freeze-thaw cycles } \\
& & 10 & 20 & 30 \\
\hline \multirow{2}{*}{ Mass variation ratio (\%) } & Site soil & -0.12 & -0.13 & -0.15 \\
& Modified soil & -0.13 & -0.15 & -0.18 \\
\hline \multirow{2}{*}{ Volume variation ratio (\%) } & Site soil & -0.62 & -0.78 & -3.58 \\
& Modified soil & -0.76 & -0.88 & -1.67 \\
\hline
\end{tabular}

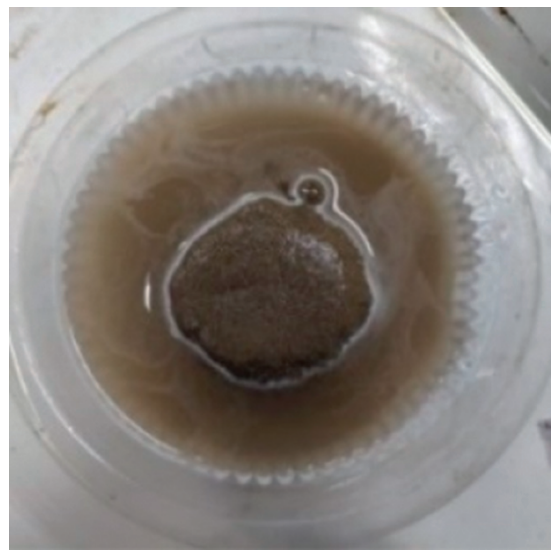

(a)

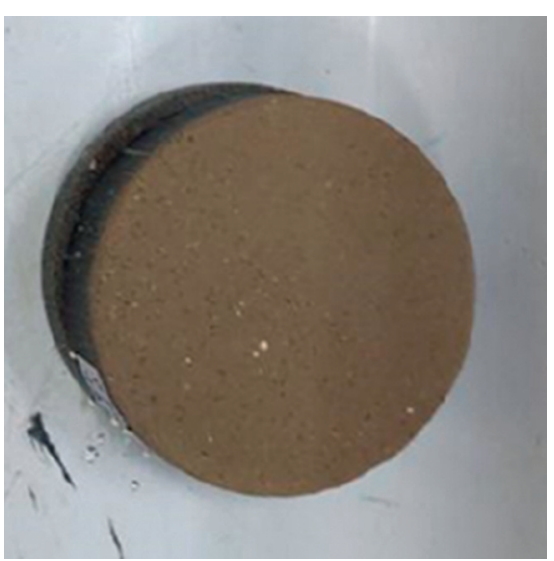

(b)

FIGURE 18: Comparative analysis of water immersion stability: (a) original site soil and (b) modified soil.

\section{Conclusion}

In this study, the restoration materials for silty earthen sites have been studied using lime and starch ether to modify the soil. A series of tests on the modified soil have been carried out, and the engineering properties of the modified soil and the original site soil have been compared. The conclusions of the study are listed as follows.

The shear strength and compressive ability of soil could be improved significantly by adding lime or starch ether individually. For single-mixed modified soil, the optimum lime content is $9 \%$, and the cohesion and internal friction angle of the modified silt are $72.45 \mathrm{kPa}$ and $48.6^{\circ}$, respectively. The optimal concentration of starch ether solution is $5 \%$, and the cohesion and internal friction angle of the modified silt are $80.32 \mathrm{kPa}$ and $42.3^{\circ}$, respectively. The deformation of the modified soil with the optimum content also reaches the minimum value.

Furthermore, the shear strength and compressibility of multiple-mixed modified soil were generally higher than those of single-mixed modified soil. For the multiple-mixed modified soil, when the lime content was $6 \%$ and the starch ether concentration was $5 \%$, the shear strength was found to be the largest and the compressibility was the smallest. The 
maximum values of cohesion and internal friction angle of multiple-mixed modified soil were 67.6 and $3.37 \%$ higher than those of the lime-modified soil and were 51.1 and $18.8 \%$ higher than those of the starch-ether-modified soil, respectively. Therefore, compared to those of single-mixed modified soil, the mechanical properties of multiple-mixed modified soil were significantly improved.

For the multiple-mixed modified soil with the optimum content, the environmental durability was also similar to or higher than that of the original site soil. These results clearly indicated that the main engineering properties of the optimum modified soil are generally similar to those of the original site soil. Moreover, the restoration material selected in this study also has good economic value. Therefore, it is feasible and effective to use lime together with starch ether as an efficient restoration material for earthen sites.

\section{Data Availability}

The data used to support the findings of this study are included within the article.

\section{Conflicts of Interest}

The authors declare that there are no conflicts of interest regarding the publication of this paper.

\section{Acknowledgments}

This work was funded by Shaanxi Natural Science Foundation Project (Grant no. 2020JM-235), Shaanxi Postdoctoral Research Funding Project (2017BSHEDZZ114), the Open Project of State Key Laboratory of Green Building in Western China (LSKF 201905), and Science and Technology Planning Project of Yulin Technology Division (214028170376).

\section{References}

[1] J. Kuang, "Testing study on saline wind erosion of earthen sites in the arid region of Northwest China," Master's thesis, Lanzhou University, Lanzhou, China, 2011.

[2] G. Q. Han, Experimental Study on Chemical Consolidation of Earthen Sites, China University of Geosciences Press, Beijing, China, 2nd edition, 2012.

[3] D. Kong, R. Wan, J. Chen, Y. Jing, W. Huang, and Y. Wang, "The study on engineering characteristics and compression mechanisms of typical historical earthen site soil," Construction and Building Materials, vol. 213, pp. 386-403, 2019.

[4] W. W. Chen, Z. Q. Guo, Y. R. Xu, P. F. Chen, S. Zhang, and F. Ye, "Laboratory tests on rammed earth samples of earthen sites instilled by reinforcement material SH," Chinese Journal of Geotechnical Engineering, vol. 37, no. 8, pp. 1517-1523, 2015.

[5] X. D. Wang, "New progress in research on key technologies of soil relic protection in arid environment in China," Dunhuang Research, vol. 112, no. 6, pp. 6-12, 2008.

[6] Z. X. Li, L. Y. Zhao, and M. L. Sun, "Diseases and PS reinforcement of the silk road site in China," Chinese Journal of Rock Mechanics and Engineering, vol. 28, no. 5, pp. 1047-1054, 2009, in Chinese.
[7] C. S. Peters and M. Mangel, "New methods for the problem of collective ruin," SIAM Journal on Applied Mathematics, vol. 50, no. 5, pp. 1442-1456, 1990.

[8] C. Giacomo, "Chemical surface tremens and capping techniques of earthen structures: along-term evaluation," in Proceedings of the 6th International Conference on the Conservation of Earthen Architecture, pp. 267-270, Las Cruces, New Mexico, October 1990.

[9] China Translation Corporation, "Appropriate Technologies" in the Conservation of Cultural Property, China Architecture \& Building Press, Beijing, China, 1985.

[10] D. Song and S. Yao, "A study of the interpretation and location of the ruins of the ancient graves using remote sensing technique," Proceedings of SPIE, vol. 1395, no. 2, pp. 9649732, 1990.

[11] N. Degirmenci and B. Baradan, "Chemical resistance of Pozzolanic plaster for earthen walls," Construction and Building Materials, vol. 19, no. 7, pp. 536-542, 2005.

[12] M. G. Arab, R. A. Mousa, A. R. Gabr, A. M. Azam, S. M. ElBadawy, and A. F. Hassan, "Resilient behavior of sodium alginate-treated cohesive soils for pavement applications," Journal of Materials in Civil Engineering, vol. 31, no. 1, Article ID 04018361, 11 pages, 2019.

[13] Y. Liu, M. Chang, Q. Wang et al., "Use of sulfur-free lignin as a novel soil additive: a multi-scale experimental investigation," Engineering Geology, vol. 269, Article ID 105551, 2020.

[14] S. Wang, A. K. Leung, V. K. Gadi, R. Hussain, A. Garg, and S. Sekharan, "Water retention and desiccation potential of lignocellulose-based fiber-reinforced soil," Journal of Geotechnical And Geoenvironmental Engineering, vol. 55, no. 4, pp. 342-354, 2020.

[15] S. Adhikari, M. J. Khattak, and B. Adhikari, "Mechanical characteristics of soil-RAP-geopolymer mixtures for road base and subbase layers," International Journal of Pavement Engineering, vol. 21, no. 4, pp. 483-496, 2020.

[16] X. H. Bao, "The formation of modern Chinese cultural relics protection consciousness," Relics and Museology, vol. 3, pp. 75-80, 2000.

[17] China Cultural Heritage Research Institute, Chinese Cultural Relics Protection and Restoration Technology, Science Press, Beijing, China, 2009.

[18] M. L. Sun, "Current status and development of research on earth relic protection," Sciences of Conservation and Archaeology, vol. 19, no. 4, pp. 64-70, 2007.

[19] K. Z. Huang, "Protection of Chinese cultural relics science and technology towards the 21st century," Dunhuang Research, vol. 1, pp. 5-9, 2000.

[20] Z. R. Zhang, L. X. Liu, Z. H. Liu et al., "Experiments on the protection of ancient earth ruins," Journal of Northwest University (Natural Science Edition), vol. 20, no. 3, pp. 43-49, 1990.

[21] Z. R. Zhang and B. C. Fan, The Protection of Several Qin Earth Ruins and the Study of Qin Dynasty, Shaanxi People's Education Press, Xi'an, China, 1996.

[22] Z. X. Li and X. D. Wang, "Conservation of the earth and stone cultural relics along the Silk road," in Proceedings of the 15th Academic Conference of Chinese Society of Rock Mechanics and Engineering, vol. 9, pp. 547-551, Shanghai, China, 1998.

[23] Z. X. Li, X. D. Wang, and L. M. Hao, "Research on the earth conservation of indoor structure sites," Dunhuang Research, vol. 4, pp. 144-150, 1998.

[24] B. M. Su, Z. X. Li, and Z. D. Hu, "A preliminary study on the mechanism of PS acting on soil sites," Dunhuang Research, vol. 1, pp. 30-35, 2000. 
[25] Z. J. Zhang, Research on the Protection of Qin Terracotta Warriors and Horses, Shaanxi People's Education Publishing House, Xi'an, China, 1996.

[26] W. Shan, K. S. Zhang, and S. X. Liu, Reinforcement of Qinhua No. 1 Pit Charcoal Site and Study of Qin Dynasties, Shaanxi People's Education Publishing House, Xi'an, China, 1996.

[27] Z. X. Li, X. D. Wang, Z. J. Zhang, T. Zhou, and F. He, "Reinforcement test of terracotta pit soil site," Dunhuang Research, vol. 4, pp. 151-158, 1998.

[28] Z. Z. Pang, "Strengthening the cracks in ancient ruins of Jiaohe river," Cultural Relics, vol. 11, pp. 88-91, 1997.

[29] Z. X. Li, X. D. Wang, and L. Tian, "Reinforcement test of soil site of Jiaohe ancient city," Dunhuang Research, vol. 3, pp. 171-176, 1997.

[30] X. J. Chai, Q. H. Qian, Z. P. Yang, S. Hayashi, and K. Matsunaga, "An example of reinforced concrete site engineering by bit chemical grouting," Chinese Journal of Rock Mechanics and Engineering, vol. 28, no. S1, pp. 2980-2985, 2009, in Chinese.

[31] Z. X. Li, "Stability and strength of soil-reinforced stone relics reinforced by PS," Dunhuang Research, vol. 3, pp. 96-111, 1996.

[32] H. Y. Zhao, X. D. Wang, Z. X. Li et al., "Influence of modulus and concentration of PS material on reinforcement effect of soil building sites in arid area," Chinese Journal of Rock Mechanics and Engineering, vol. 25, no. 3, pp. 557-562, 2006.

[33] F. G. He, W. W. Yan, H. Y. Zhao, M. L. Sun, and J. K. Zhang, "Experimental research of PS reinforcing earthen architecture," Journal of Central South University (Science and Technology), vol. 41, no. 3, pp. 1132-1138, 2010.

[34] C. X. Yuan, "Review of soil relics protection materials," Dunhuang Research, vol. 6, pp. 103-105, 2002.

[35] S. L. Zhou, Exploration of Soil Relics Protection Materials-Development of Non-aqueous Dispersion Materials and Reinforcement of Soil Sites, Cultural Relics Publishing House, Beijing, China, 2011.

[36] H. T. Peng, Q. Zhang, N. S. Li, and D. F. Wang, "Effect of glutinous rice syrup on the properties of triple soil for restoration of soil sites," Journal of Building Materials, vol. 14, no. 5, pp. 718-722, 2011.

[37] X. J. Ji, M. Q. Song, and M. Pang, "Experimental study on physical and mechanical properties of glutinous rice ternary soil," Architecture Technology, vol. 44, no. 6, pp. 540-543, 2013.

[38] Y. Y. Zeng, B. J. Zhang, and X. L. Liang, "Research on the performance and mechanism of traditional building marl reinforcement materials," Sciences of Conservation and Archaeology, vol. 20, no. 2, pp. 1-7, 2008.

[39] Y. G. Xie, "Mechanical behavior of glutinous rice mortar and failure mechanism of ancient seawall," Master's thesis, Zhejiang University, Hangzhou, China, 2013.

[40] G. F. Wei, B. J. Zhang, F. W. Yang, B. Z. Hu, B. Chen, and X. D. Wang, "Calcium-based hydraulic liquid reinforcing agents used to reinforce the protection of wet soil sites," Rock and Soil Mechanics, vol. 33, no. 3, pp. 702-712, 2012.

[41] C. L. Yin, W. Zhang, X. L. Jiang, and Z. Y. Huang, "Effects of initial water content on microstructure and mechanical properties of lean clay soil stabilized by compound calciumbased stabilizer," Materials, vol. 11, no. 10, p. 1933, 2018.

[42] M. Al-Mukhtar, A. Lasledj, and J.-F. Alcover, "Behaviour and mineralogy changes in lime-treated expansive soil at $20^{\circ} \mathrm{C}$," Applied Clay Science, vol. 50, no. 2, pp. 191-198, 2010.
[43] D. I. Boardman, S. Glendinning, and C. D. F. Rogers, "Development of stabilisation and solidification in lime-clay mixes," Géotechnique, vol. 51, no. 6, pp. 533-543, 2001.

[44] E. B. Pancar and M. V. Akpinar, "Comparison of effects of using geosynthetics and lime stabilization to increase bearing capacity of unpaved road subgrade," Advances in Materials Science and Engineering, vol. 2016, Article ID 7129356, 8 pages, 2016.

[45] Z. M. Mo, "Study on molecular structure and physicochemical properties of glutinous rice starch," Master's thesis, Huazhong University of Science and Technology, Wuhan, China, 2010.

[46] Ministry of Housing and Urban Rural Development of the People's Republic of China, Standard for Soil Test Method (GB/T 50123-2019), China Planning Press, Beijing, China, 2019.

[47] H. Z. Mi, H. W. Zhu, and H. Wang, "Variation pattern of strength of 2:8 lime-soil based on its triaxial test," Journal of Lanzhou University of Technology, vol. 35, no. 4, pp. 117-120, 2009, in Chinese.

[48] X. Zhou and Y. F. Xu, "The mechanical properties of limestabilized soils," Low Temperature Architecture Technology, vol. 40, no. 7, pp. 99-102, 2018, in Chinese.

[49] A. M. Yu and T. Q. Xu, "Research on formation mechanism of limestone soil strength," Northern Transportation, vol. 10, pp. 61-63, 2018, In Chinese.

[50] Y. Wang and L. M. Gao, "Effect of starch ether on the properties of ceramic tile adhesive," New Building Materials, vol. 4, pp. 62-64, 2017.

[51] S. N. Tian, "Preparation and study on thin-layer extra fine sand mortar for bonding tiles," Master's thesis, Chongqing University, Chongqing, China, 2008. 